\title{
KESESUAIAN JENIS POHON DI HUTAN KOTA PEKANBARU
}

\author{
Hadinoto, Eni Suhesti, Eno Suwarno \\ Staf Pengajar Fakultas Kehutanan Universitas Lancang Kuning \\ Jln. Yos Sudarso Km. 8 Rumbai Pekanbaru Riau Telp./Fax. (0761) 54092 \\ Email : hadinoto@unilak.ac.id, hesti1170@yahoo.co.id,dan enosuwarno@gmail.com
}

\begin{abstract}
City forest with many stratum provides the surrounding environment is relatively more comfortable than the low stratum. In order to achieve success in achieving management objectives, the types planted in urban forest development and development programs should be selected based on the consideration that crops grow well and can cope with emerging environmental problems in the region. Identifying the suitability of existing tree species in urban forest is intended to obtain maximum plant growth and municipal forest benefits. The purpose of this study is to identify the suitability of forest conifer tree species in Pekanbaru City. Data collection is done by survey in the field by defecting the existing tree species in urban forest. The result of tree species identification is used to evaluate the suitability of tree species of forest forest. A literature study was conducted to find out the growing requirements and characteristics of tree species of urban forest in the study sites. Data analysis is conducted by considering silvicultural, management and aesthetic requirements. Based on this criteria are made that is appropriate, quite appropriate, and not appropriate. Based on the results of the study can be summarized as follows: The type of urban forest in Pekanbaru City is the protection and recreation with the form of clusters / gangs and paths; There are 15 species of trees that have appropriate criteria based on silvicultural, management and aesthetic requirements; There are 15 species of trees capable of controlling air pollution.
\end{abstract}

Keywords: urban forest; tree species; conformity

\section{PENDAHULUAN}

\section{Latar Belakang}

Pembangunan kota sering
banyak dicerminkan oleh adanya
perkembangan fisik kota yang lebih
banyak ditentukan oleh sarana dan
prasarana yang ada. Gejala
pembangunan kotan pada masa lalu memiliki kecenderungan untuk meminimalkan ruang terbuka hijau dan juga menghilangkan wajah alam.
Lahan-lahan banyak dialih-fungsikan menjadi pusat-pusat perbelanjaan, pemukiman, tempat rekreasi, industri dan lain-lain. Semakin tidak harmonisnya hubungan manusia dengan alam mengakibatkan keadaan lingkungan di perkotaan maju secara ekonomi tetapi mengalami kemunduran secara ekologi. Padahal kestabilan ekologi di perkotaan sangat penting, sama pentingnya dengan kestabilan 
ekonomi. Hijaunya kota tidak hanya menjadikan kota itu indah dan sejuk namun aspek kelestarian, keserasian, keselarasan dan keseimbangan sumberdaya alam, yang selanjutnya akan memberikan jasa-jasa berupa kenyamanan, kesegaran, kota bebas polusi, bebas kebisingan dan lainnya.

Hutan Kota dapat memberikan kota yang nyaman sehat dan indah (estetis). Kita sangat membutuhkan hutan kota, untuk perlindungan dari berbagai masalah lingkungan perkotaan. Hutan kota mempunyai banyak fungsi (kegunaan dan manfaat). Hal ini tidak terlepas dari peranan tumbuh-tumbuhan di alam. Tumbuh-tumbuhan sebagai produsen pertama dalam ekosistem, mempunyai berbagai macam kegiatan metabolisme untuk dapat hidup, tumbuh dan berkembang. Kegiatan metabolisme tumbuh-tumbuhan dimaksud telah memberikan keuntungan dalam kehidupan kita. Tidak ada satu makhlukpun yang dapat hidup tanpa tumbuh-tumbuhan.

Hutan kota dapat memberikan kenyamanan dan kenikmatan kepada kita. Apalagi bila kita dapat mengembangkan dan membangun hutan kota yang berstruktur, dengan keanekaragam jenis tumbuh-tumbuhan dan jumlah yang banyak serta ditata dengan baik. Diharapkan hutan kota dapat memenuhi tingkat kenyamanan yang dikehendaki, karena hutan kota dapat memodifikasi iklim mikro. Hutan kota yang berstrata banyak memberikan lingkungan sekitarnya relatif lebih nyaman daripada yang berstrata rendah, dan di dalam hutan akan kita rasakan lingkungannya lebih nyaman dibandingkan dengan di luar hutan kota. Guna mendapatkan keberhasilan dalam mencapai tujuan pengelolaan lingkungan hidup di perkotaan, jenis yang ditanam dalam program pembangunan dan pengembangan hutan kota hendaknya dipilih berdasarkan pertimbangan agar tanaman tumbuh dengan baik dan dapat menanggulangi masalah lingkungan yang muncul di wilayah tersebut. Mengidentifikasi kesesuaian jenis pohon yang ada di hutan kota dimaksudkan untuk mendapatkan pertumbuhan tanaman dan manfaat hutan kota yang maksimal.

\section{Rumusan Masalah}

Saat ini banyak kendala dalam membangun hutan kota. Antara lain, lahan untuk hutan kota yang semakin hari semakin sedikit dan harga lahan di kota semakin hari semakin mahal. Hal 
lainnya, terbentur kepada persepsi dari para perancang dan pelaksana pembangunan maupun dari lapisan masyarakat lainnya terhadap hutan kota belum sama dan belum terbangun. Agar hutan kota bisa berdiri di suatu kota, semua pihak harus menyamakan persepsi baik dari perancang, pelaksana, maupun dari pengambil keputusan dan masyarakat. Semua pihak harus sepakat bahwa hutan kota dapat dibangun dan dikembangkan di mana saja, sesuai dengan bentuk dan struktur hutan kota. Data dan informasi tentang jenis pohon yang ada di hutan kota sangat diperlukan untuk mendapatkan manfaat hutan kota yang maksimal.

\section{Tujuan Penelitian}

Tujuan penelitian ini adalah untuk menidentifikasi kesesuaian jenis pohon penyusun hutan kota di Kota Pekanbaru.

\section{Manfaat Penelitian}

Manfaat dari penelitian ini adalah menyediakan data dan informasi tentang jenis pohon yang sesuai dalam pembangunan hutan kota untuk mendapatkan manfaat yang maksimal

\section{METODE PENELITIAN}

Penelitian ini dilakukan di Hutan Kota Pekanbaru (Hutan Kota JIn. Diponegoro (bentuk gerombol), Hutan Kota Jln. Arifin Ahmad (bentuk jalur)).

\section{Alat dan Bahan}

Objek yang diteliti pada penelitian ini adalah jenis-jenis pohon di Hutan Kota, Kota Pekanbaru. thally sheet sebagai bahan mencatat data. Peralatan yang digunakan adalah : pita ukur dan meteran, kamera, alat tulis dan dibantu oleh pengenal jenis pohon.

\section{Metode Pengumpulan Data}

Pengumpulan data dilakukan dengan cara survey di lapangan dengan mencacat jenis pohon yang ada di hutan kota.

\section{Analisis Data}

Mengidentifikasi kesesuaian jenis pohon yang ada di hutan kota dengan cara survei lapangan yang dilakukan untuk mengetahui jenis pohon penyusun hutan kota. Survei ini dilakukan dengan cara sensus pohon. Kriteria pohon yang disensus adalah tumbuhan pada tingkatan tiang dan pohon yang memiliki $\mathrm{DBH} \geq 10 \mathrm{~cm}$ dan tinggi pohon > 3 meter. Hasil identifikasi jenis pohon digunakan untuk melakukan 
evaluasi terhadap kecocokan jenis pohon penyusun hutan kota. Studi pustaka dilakukan untuk mengetahui persyaratan tumbuh dan karakteristik jenis-jenis pohon penyusun hutan kota di lokasi penelitian. Menurut Indriyanto (2006), analisis kecocokan jenis pohon penyusun hutan kota dilakukan dengan pengolahan data dan tabulasi, kemudian dianalisis secara deskriptif. Pada setiap tipe hutan kota diklasifikasi menjadi tiga kelas, yaitu sesuai, cukup sesuai, dan tidak sesuai dengan penentuan interval kelas sebagai berikut (Indriyanto, 2006). Interval Kelas $=$

Nilai Tertinggi - Nilai Terendah

Jumlah Kelas

Komponen penentuan skor untuk bentuk vegetasi hutan kota berdasarkan teori dari Indriyanto (2006) dan Saebo et al. (2005) sebagai berikut:

\section{Persyaratan Silvikultural}

Menurut Indriyanto (2006), untuk memenuhi fungsi hutan kota secara optimal, maka jenis pohon hutan kota harus memenuhi persyaratan silvikultural, diantaranya adalah berada pada tempat tumbuh yang sesuai dengan kebutuhan pertumbuhannya (kondisi iklim dan edafis), dapat tumbuh pada tanah miskin hara, mampu memulihkan kesuburan tanah, tahan terhadap serangan hama dan penyakit, spesies tumbuhan yang selalu hijau, batang pokok dan cabang kuat sehingga tidak mudah tumbang dan patah, akar tidak merusak jalan, beton, dan bangunan yang ada di sekitarnya. Sementara Saebo et al. (2005), menambahkan bahwa jenis pohon untuk hutan kota harus toleran terhadap suhu tinggi dan penyinaran matahari yang kuat serta toleran terhadap kekurangan air. Dengan demikian komponen skor untuk pemenuhan persyaratan silvikultural seperti pada Tabel 1 berikut.

Tabel 1. Komponen, Kriteria dan Skor Untuk Pemenuhan Persyaratan Silvikultural Dalam Pemilihan Jenis Pohon Hutan Kota

\begin{tabular}{|c|c|c|}
\hline Komponen & Kriteria & Skor \\
\hline \multirow{2}{*}{$\begin{array}{l}\text { Ketinggian } \\
\text { tempat }\end{array}$} & $0-5.000 \mathrm{mdpl}$ & 2 \\
\hline & $>5.000 \mathrm{mdpl}$ & 1 \\
\hline \multirow[b]{2}{*}{ Curah Hujan } & $1.200-2.000 \mathrm{~mm} / \mathrm{thn}$ & 2 \\
\hline & $\begin{array}{l}<1.200 \text { dan }>2.000 \\
\mathrm{~mm} / \mathrm{thn}\end{array}$ & 1 \\
\hline \multirow{2}{*}{$\begin{array}{l}\text { Toleran } \\
\text { terhadap } \\
\text { tanah miskin } \\
\text { hara }\end{array}$} & Toleran & 2 \\
\hline & Tidak Toleran & 1 \\
\hline \multirow{2}{*}{$\begin{array}{l}\text { Sifat } \\
\text { memulihkan } \\
\text { kesuburan } \\
\text { tanah }\end{array}$} & $\begin{array}{l}\text { Mampu menyuburkan } \\
\text { tanah }\end{array}$ & 2 \\
\hline & $\begin{array}{l}\text { Tidak mampu } \\
\text { menyuburkan tanah }\end{array}$ & 1 \\
\hline \multirow{2}{*}{$\begin{array}{l}\text { Tahan hama } \\
\text { dan penyakit }\end{array}$} & Tahan & 2 \\
\hline & Tidak tahan & 1 \\
\hline \multirow{2}{*}{$\begin{array}{l}\text { Sifat } \\
\text { menggugurkan } \\
\text { daun }\end{array}$} & $\begin{array}{l}\text { Selalu hijau } \\
\text { (evergreen) }\end{array}$ & 2 \\
\hline & Menggugurkan daun & 1 \\
\hline $\begin{array}{l}\text { Ketahanan } \\
\text { batang pokok }\end{array}$ & $\begin{array}{l}\text { Tidak mudahtumbang } \\
\text { dan patah }\end{array}$ & 2 \\
\hline
\end{tabular}




\begin{tabular}{llc}
\hline \multicolumn{1}{c}{ Komponen } & \multicolumn{1}{c}{ Kriteria } & Skor \\
\hline $\begin{array}{l}\text { dan } \\
\text { percabangan } \\
\text { terhadap angin }\end{array}$ & $\begin{array}{l}\text { Mudah tumbang dan } \\
\text { patah }\end{array}$ & 1 \\
\hline $\begin{array}{l}\text { Kondisi } \\
\text { perakaran } \\
\text { terhadap } \\
\text { bangunan di } \\
\text { sekitarnya }\end{array}$ & $\begin{array}{l}\text { Tidak } \\
\text { merusak/mengganggu }\end{array}$ & 2 \\
\cline { 2 - 3 } $\begin{array}{l}\text { Toleransi } \\
\text { terhadap suhu } \\
\text { tinggi }\end{array}$ & Merusak/mengganggu & 1 \\
\cline { 2 - 3 } $\begin{array}{l}\text { Toleransi } \\
\text { terhadap } \\
\text { penyinaran } \\
\text { matahari yang } \\
\text { kuat }\end{array}$ & Toleran & Tidak Toleran \\
\cline { 2 - 3 } $\begin{array}{ll}\text { Toleransi } \\
\text { terhadap } \\
\text { kekurangan air }\end{array}$ & Tidak Toleran & 1 \\
\cline { 2 - 3 } $\begin{array}{l}\text { Sumber : Saebo et al (2005) \& Indriyanto (2006) } \\
\end{array}$ & Tidak Toleran \\
\hline
\end{tabular}

\section{Persyaratan Manajemen}

Menurut Indriyanto (2006), cara penanaman spesies tumbuhan yang dipilih harus mudah, pemeliharaannya mudah dan murah, pengamanan dan pemanfaatannya mudah. Sementara menurut Saebo et al. (2005), jenis pohon yang dipilih untuk pengembangan hutan kota harus memiliki fungsi yang diharapkan sesuai dengan tujuan pembangunan hutan kota, yaitu bertajuk tebal dan rapat sehingga dapat berfungsi sebagai tanaman peneduh, bertajuk kuat dan rapat sehingga bisa berfungsi sebagai tanaman pelindung angin, serta berkemampuan tinggi dalam pengurangan pencemaran lingkungan perkotaaan (udara, air, tanah). Dengan demikian, komponen skor untuk pemenuhan persyaratan manajemen adalah sebagaimana ditampilkan pada Tabel 2.

Tabel 2. Komponen, Kriteria dan Skor Untuk Pemenuhan Persyaratan Manajemen Dalam Pemilihan

\begin{tabular}{|c|c|c|}
\hline Komponen & Kriteria & Skor \\
\hline \multirow{2}{*}{ Cara penanaman } & Mudah & 2 \\
\hline & Sulit & 1 \\
\hline \multirow{2}{*}{ Cara pemeliharaan } & $\begin{array}{l}\text { Mudah dan } \\
\text { murah }\end{array}$ & 2 \\
\hline & $\begin{array}{l}\text { Tidak mudah } \\
\text { dan mahal }\end{array}$ & 1 \\
\hline \multirow{2}{*}{$\begin{array}{l}\text { Cara } \\
\text { pengamannya }\end{array}$} & Mudah & 2 \\
\hline & Tidak Mudah & 1 \\
\hline \multirow{2}{*}{$\begin{array}{l}\text { Cara } \\
\text { Pemanfaatannya }\end{array}$} & Mudah & 2 \\
\hline & Tidak Mudah & 1 \\
\hline \multirow{2}{*}{$\begin{array}{l}\text { Fungsi tajuk } \\
\text { sebagai peneduh } \\
\text { (tebal dan rapat) }\end{array}$} & $\begin{array}{l}\text { Baik sebagai } \\
\text { peneduh (tajuk } \\
\text { tebal dan rapat) }\end{array}$ & 2 \\
\hline & $\begin{array}{l}\text { Kurang baik } \\
\text { sebagai } \\
\text { peneduh (tahuj } \\
\text { tipis dan ringan) }\end{array}$ & 1 \\
\hline \multirow{2}{*}{$\begin{array}{l}\text { Fingsi tajuk } \\
\text { sebagai pelindung } \\
\text { angin (kuat dan } \\
\text { rapat) }\end{array}$} & $\begin{array}{l}\text { Baik sebagai } \\
\text { pelindung angin } \\
\text { (tajuk kuat dan } \\
\text { rapat) }\end{array}$ & 2 \\
\hline & $\begin{array}{l}\text { Kurang baik } \\
\text { sebagai } \\
\text { pelindung angin } \\
\text { (tajuk tidak kuat } \\
\text { dan ringan) }\end{array}$ & 1 \\
\hline \multirow{2}{*}{$\begin{array}{l}\text { Kemampuan dalam } \\
\text { pengurangan } \\
\text { pencemaran }\end{array}$} & Tinggi & 2 \\
\hline & Rendah & 1 \\
\hline
\end{tabular}

\section{Persyaratan Estetika}

Menurut Indriyanto (2006), jenis pohon yang akan ditanam pada hutan kota harus memiliki habitus yang menampakkan kesesuaian dengan tujuan keindahan. Sementara menurut Saebo et al. (2005), selain fungsi estetika/keindahan, jenis pohon yang 
dipilih dalam pengembangan hutan kota harus mendukung fungsi pendidikan/ edukasi dan kesehatan serta kenyamanan masyarakat di sekitarnya, diantaranya adalah:

a. memiliki tajuk, percabangan, daun dan/atau bunga yang indah sehingga berfungsi sebagai penambah estetika atau keindahan lingkungan perkotaan,

b. memiliki fungsi sebagai sarana pendidikan,

c. memiliki buah berukuran relatif kecil sehingga ketika jatuh tidak membahayakan manusia atau merusak fasilitas/bangunan di sekitarnya

d. tidak menghasilkan getah yang beracun atau berbahaya bagi makhluk hidup,

e. tidak menghasilkan serbuk sari yang berpotensi menimbulkan alergi bagi manusia.

Dengan demikian, komponen skor untuk pemenuhan persyaratan estetika adalah sebagaimana ditampilkan pada Tabel 3.
Tabel 3. Komponen, Kriteria dan Skor Untuk Pemenuhan Persyaratan Estetika Dalam Pemilihan Jenis Pohon Hutan Kota

\begin{tabular}{|c|c|c|}
\hline Komponen & Kriteria & $\underset{r}{\text { Sko }}$ \\
\hline \multirow{2}{*}{$\begin{array}{l}\text { Habitus ( tajuk, } \\
\text { percabangan, } \\
\text { daun dan/atau } \\
\text { bunga) }\end{array}$} & Indah & 2 \\
\hline & Tidak indah & 1 \\
\hline \multirow{2}{*}{$\begin{array}{l}\text { Fungsi sebagai } \\
\text { sarana pendidikan }\end{array}$} & $\mathrm{Ya}$ & 2 \\
\hline & Tidak & 1 \\
\hline \multirow{2}{*}{ Ukuran buah } & $\begin{array}{l}\text { Buah berukuran } \\
\text { relatif kecil }\end{array}$ & 2 \\
\hline & $\begin{array}{l}\text { Buah berukuran } \\
\text { besar }\end{array}$ & 1 \\
\hline \multirow{2}{*}{$\begin{array}{l}\text { Getah } \\
\text { beracun/berbahay } \\
\text { a }\end{array}$} & $\begin{array}{l}\text { Tidak } \\
\text { menghasilkan }\end{array}$ & 2 \\
\hline & $\begin{array}{l}\text { Getah } \\
\text { beracun/berbahay } \\
\text { a }\end{array}$ & 1 \\
\hline \multirow{2}{*}{$\begin{array}{l}\text { Potensi alergi dari } \\
\text { serbuk sari }\end{array}$} & $\begin{array}{l}\text { Tidak berpotensi } \\
\text { alergi }\end{array}$ & 2 \\
\hline & Berpotensi alegi & 1 \\
\hline \multicolumn{3}{|c|}{ Uumber : Saebo et al (2005) \& Indriyanto (2006) } \\
\hline Untuk & menentukan & pria \\
\hline
\end{tabular}

kesesuaian dilakukan penghitungan terhadap skor setiap jenis pohon yang diperoleh dari hasil survei lapangan. Setelah itu, setiap jenis pohon diurutkan berdasarkan skor tertinggi sampai dengan terendah lalu dikelompokkan menjadi tiga kelas kriteria kesesuaian sebagai berikut.

Kriteria kesesuaian:

a. TIDAK SESUAI (skor : 23 - 30,33)

b. CUKUP SESUAl (skor : >30,33 38,33 )

c. SESUAI (skor : >38,33 - 46)

Untuk mengetahui jenis-jenis pohon yang sesuai dengan kondisi 
persyaratan tumbuh dan toleran terhadap pencemaran udara dilakukan dengan studi pustaka. Jenis pohon yang dianggap sesuai dalam pengembangan hutan kota adalah jenis pohon yang memiliki kemampuan tinggi dalam penyerapan polutan dan memiliki daya tahan yang tinggi (toleran) terhadap paparan polutan di lokasi penelitian. Pemilihan jenis pohon penyusun hutan kota yang tepat harus mempertimbangkan faktor tempat tumbuh, faktor ekonomi dan faktor sosial (Miller, 1997). Pemilihan jenis pohon pada setiap tipe hutan kota akan bervariasi mengingat tujuan pengembangan hutan kota pada setiap tipe hutan kota juga beragam.
HASIL DAN PEMBAHASAN

Jenis Pohon Penyusun Hutan Kota di Kota Pekanbaru

Berdasar

pada

hasil

pengamatan di Kota Pekanbaru terdapat tipe hutan kota untuk perlindungan dan rekreasi. Sedangkan bentuknya mengelompok/ gerombol dan jalur. Pengamatan jenis pohon hutan kota untuk bentuk mengelompok/ gerombol dilakukan di Hutan Kota Diponegoro dan untuk bentuk jalur di Jalan Arifin Ahmad. Terdapat 39 jenis pohon penyusun hutan kota dengan 21 famili di Kota Pekanbaru, dengan rincian di Hutan Kota Diponegoro 25 jenis dengan 17 famili dan di Jalan Arifin Ahmad 23 jenis dengan 14 famili. Famili Fabaceae mendominasi dengan 6 jenis/ species, famili Myrtaceae dengan 4 jenis/ species. Jenis pohon penyusun hutan kota seperti tercantum pada Tabel 4 .

Tabel 4. Jenis Pohon Penysun Hutan Kota dan Kesesuaiannya di Kota Pekanbaru

\begin{tabular}{llllcccc}
\hline No & \multicolumn{1}{c}{$\begin{array}{c}\text { Nama Jenis } \\
\text { Pohon }\end{array}$} & \multicolumn{1}{c}{ Famili } & \multicolumn{1}{c}{ Lokasi } & Skor & Ket. & \\
\cline { 2 - 6 } & IImiah & Daerah/lokal & & $\begin{array}{c}\text { Hutan Kota } \\
\text { Diponegoro }\end{array}$ & $\begin{array}{c}\text { Jln. } \\
\text { Arifin } \\
\text { Ahmad }\end{array}$ & \\
\hline 1 & $\begin{array}{l}\text { Acacia } \\
\text { auriculiformis }\end{array}$ & $\begin{array}{l}\text { Akasia } \\
\text { Aurikulformis }\end{array}$ & Fabaceae & $\sqrt{ }$ & $\sqrt{ }$ & 38 & CUKUP \\
\hline 2 & $\begin{array}{l}\text { Acacia } \\
\text { mangium }\end{array}$ & $\begin{array}{l}\text { Akasia } \\
\text { Mangium }\end{array}$ & Fabaceae & $\sqrt{ }$ & $\sqrt{ } 38$ & CUKUP \\
\hline 3 & $\begin{array}{l}\text { Adenanthera } \\
\text { malayana }\end{array}$ & Saga & Fabaceae & - & $\sqrt{ }$ & 43 & SESUAI \\
\hline 4 & $\begin{array}{l}\text { Alstonia } \\
\text { pneumatophora }\end{array}$ & Pulai Rawa & Apocynaceae & $\sqrt{ }$ & - & 39 & SESUAI \\
\hline 5 & Alstonia & Pulai & Apocynaceae & $\sqrt{ }$ & $\sqrt{ }$ & 39 & SESUAI \\
\hline
\end{tabular}




\begin{tabular}{|c|c|c|c|c|c|c|c|}
\hline \multirow{3}{*}{ No } & $\begin{array}{l}\text { Nama Jenis } \\
\text { Pohon }\end{array}$ & Famili & Lokasi & Skor & Ket. & & \\
\hline & IImiah & \multirow[t]{2}{*}{ Daerah/lokal } & & \multirow[t]{2}{*}{$\begin{array}{l}\text { Hutan Kota } \\
\text { Diponegoro }\end{array}$} & \multirow[t]{2}{*}{$\begin{array}{c}\text { Jln. } \\
\text { Arifin } \\
\text { Ahmad } \\
\end{array}$} & & \\
\hline & scholaris & & & & & & \\
\hline 6 & $\begin{array}{l}\text { Aquilaria } \\
\text { malaccensis }\end{array}$ & Gaharu & Thymelaceae & $\sqrt{ }$ & - & 38 & $\begin{array}{l}\text { CUKUP } \\
\text { SESUAI }\end{array}$ \\
\hline 7 & $\begin{array}{l}\text { Artocarpus } \\
\text { heterophylla }\end{array}$ & Nangka & Moraceae & $\sqrt{ }$ & $\sqrt{ }$ & 37 & $\begin{array}{l}\text { CUKUP } \\
\text { SESUAI }\end{array}$ \\
\hline 8 & Artocarpus sp. & Tempunik & Moraceae & $\sqrt{ }$ & - & 37 & $\begin{array}{l}\text { CUKUP } \\
\text { SESUAI }\end{array}$ \\
\hline 9 & $\begin{array}{l}\text { Calophyllum } \\
\text { inophyllum }\end{array}$ & Bintangur & Guttiferae & $\sqrt{ }$ & - & 38 & $\begin{array}{l}\text { CUKUP } \\
\text { SESUAI }\end{array}$ \\
\hline 10 & $\begin{array}{l}\text { Casuarina } \\
\text { equisetifolia }\end{array}$ & Cemara & Casuarinaceae & - & $\sqrt{ }$ & 44 & SESUAI \\
\hline 11 & $\begin{array}{l}\text { Cinnamomum } \\
\text { sp. }\end{array}$ & Medang & Lauraceae & $\sqrt{ }$ & - & 38 & $\begin{array}{l}\text { CUKUP } \\
\text { SESUAI }\end{array}$ \\
\hline 12 & Durio zibetinus & Durian & Bombacaceae & $\sqrt{ }$ & - & 35 & $\begin{array}{l}\text { CUKUP } \\
\text { SESUAI }\end{array}$ \\
\hline 13 & Eucalyptus sp. & Eukaliptus & Myrtaceae & $\sqrt{ }$ & - & 38 & $\begin{array}{l}\text { CUKUP } \\
\text { SESUAI }\end{array}$ \\
\hline 14 & Evodia lucida & $\begin{array}{l}\text { Tenggek } \\
\text { Burung }\end{array}$ & Rutaceae & $\sqrt{ }$ & - & 41 & SESUAI \\
\hline 15 & Ficus elastica & Beringin & Moraceae & - & $\sqrt{ }$ & 43 & SESUAI \\
\hline 16 & $\begin{array}{l}\text { Geroniera } \\
\text { subaecualis }\end{array}$ & Siluk & Ulmaceae & $\sqrt{ }$ & - & 37 & $\begin{array}{l}\text { CUKUP } \\
\text { SESUAI }\end{array}$ \\
\hline 17 & Gluta renghas & Renghas & Anacardiaceae & $\sqrt{ }$ & - & 37 & $\begin{array}{l}\text { CUKUP } \\
\text { SESUAI }\end{array}$ \\
\hline 18 & Jatropha sp. & Batavia & Euphorbiaceae & - & $\sqrt{ }$ & 39 & SESUAI \\
\hline 19 & $\begin{array}{l}\text { Mangifera } \\
\text { indica }\end{array}$ & Mangga & Anacardiaceae & $\sqrt{ }$ & $\sqrt{ }$ & 37 & $\begin{array}{l}\text { CUKUP } \\
\text { SESUAI }\end{array}$ \\
\hline 20 & $\begin{array}{l}\text { Melaleuca } \\
\text { leucadendron }\end{array}$ & Kayu Putih & Myrtaceae & - & $\sqrt{ }$ & 42 & SESUAI \\
\hline 21 & $\begin{array}{l}\text { Mimusops } \\
\text { elengi }\end{array}$ & Tanjung & Sapotaceae & - & $\sqrt{ }$ & 41 & SESUAI \\
\hline 22 & $\begin{array}{l}\text { Nephelium } \\
\text { lappaceum }\end{array}$ & Rambutan & Sapindaceae & $\sqrt{ }$ & - & 38 & $\begin{array}{l}\text { CUKUP } \\
\text { SESUAI }\end{array}$ \\
\hline 23 & Palaqium gutta & Balam & Sapotaceae & $\sqrt{ }$ & - & 38 & $\begin{array}{l}\text { CUKUP } \\
\text { SESUAI }\end{array}$ \\
\hline 24 & $\begin{array}{l}\text { Paraserianthes } \\
\text { falcataria }\end{array}$ & Sengon & Fabaceae & $\sqrt{ }$ & $\sqrt{ }$ & 38 & $\begin{array}{l}\text { CUKUP } \\
\text { SESUAI }\end{array}$ \\
\hline 25 & $\begin{array}{l}\text { Peronema } \\
\text { canescens }\end{array}$ & Sungkai & Verbenaceae & $\sqrt{ }$ & - & 38 & $\begin{array}{l}\text { CUKUP } \\
\text { SESUAI }\end{array}$ \\
\hline 26 & Plumeria alba & Kamboja & Euphorbiaceae & - & $\sqrt{ }$ & 38 & $\begin{array}{l}\text { CUKUP } \\
\text { SESUAI }\end{array}$ \\
\hline 27 & $\begin{array}{l}\text { Polyalthia } \\
\text { longifolia }\end{array}$ & $\begin{array}{l}\text { Glodogan } \\
\text { Tiang }\end{array}$ & Annonaceae & - & $\sqrt{ }$ & 41 & SESUAI \\
\hline 28 & $\begin{array}{l}\text { Pometia } \\
\text { pinnata }\end{array}$ & Matoa & Sapindaceae & - & $\sqrt{ }$ & 37 & $\begin{array}{l}\text { CUKUP } \\
\text { SESUAI }\end{array}$ \\
\hline 29 & $\begin{array}{l}\text { Pterocarpus } \\
\text { indicus }\end{array}$ & Angsana & Fabaceae & $\sqrt{ }$ & $\sqrt{ }$ & 41 & SESUAI \\
\hline 30 & $\begin{array}{l}\text { Samanea } \\
\text { saman }\end{array}$ & Trembesi & Fabaceae & - & $\sqrt{ }$ & 44 & SESUAI \\
\hline 31 & Shorea sp. & Meranti & Dipterocarpaceae & $\sqrt{ }$ & - & 38 & $\begin{array}{l}\text { CUKUP } \\
\text { SESUAI }\end{array}$ \\
\hline 32 & Shorea & Balau & Dipterocarpaceae & $\sqrt{ }$ & - & 38 & CUKUP \\
\hline
\end{tabular}




\begin{tabular}{|c|c|c|c|c|c|c|c|}
\hline \multirow{3}{*}{ No } & $\begin{array}{l}\text { Nama Jenis } \\
\text { Pohon }\end{array}$ & Famili & Lokasi & Skor & Ket. & & \\
\hline & IImiah & Daerah/lokal & & $\begin{array}{l}\text { Hutan Kota } \\
\text { Diponegoro }\end{array}$ & $\begin{array}{c}\text { Jln. } \\
\text { Arifin } \\
\text { Ahmad }\end{array}$ & & \\
\hline & sumatrana & & & & & & SESUAI \\
\hline 33 & $\begin{array}{l}\text { Swietenia } \\
\text { macrophylla }\end{array}$ & Mahoni & Meliaceae & $\sqrt{ }$ & $\sqrt{ }$ & 40 & SESUAI \\
\hline 34 & $\begin{array}{l}\text { Syzygium } \\
\text { polyanthum }\end{array}$ & Salam & Myrtaceae & $\sqrt{ }$ & - & 42 & SESUAI \\
\hline 35 & $\begin{array}{l}\text { Tabebuia } \\
\text { cassinoides }\end{array}$ & $\begin{array}{l}\text { Bunga } \\
\text { Kuning }\end{array}$ & Bignoniaceae & - & $\sqrt{ }$ & 37 & $\begin{array}{l}\text { CUKUP } \\
\text { SESUAI }\end{array}$ \\
\hline 36 & $\begin{array}{l}\text { Tectona } \\
\text { grandis }\end{array}$ & Jati & Verbenaceae & - & $\sqrt{ }$ & 37 & $\begin{array}{l}\text { CUKUP } \\
\text { SESUAI }\end{array}$ \\
\hline 37 & $\begin{array}{l}\text { Terminalia } \\
\text { catappa }\end{array}$ & Ketapang & Combretaceae & $\sqrt{ }$ & $\sqrt{ }$ & 37 & $\begin{array}{l}\text { CUKUP } \\
\text { SESUAI }\end{array}$ \\
\hline 38 & $\begin{array}{l}\text { Terminalia } \\
\text { mantaly }\end{array}$ & $\begin{array}{l}\text { Ketapang } \\
\text { Kencana }\end{array}$ & Combretaceae & - & $\sqrt{ }$ & 37 & $\begin{array}{l}\text { CUKUP } \\
\text { SESUAI }\end{array}$ \\
\hline 39 & Zyzygium sp. & Pucuk Merah & Myrtaceae & - & $\sqrt{ }$ & 42 & SESUAI \\
\hline
\end{tabular}

\section{Sumber: Data Olahan 2018}

Berdasar pada Tabel 4 di atas terlihat bahwa jenis pohon penyusun hutan kota di Kota Pekanbaru masih relatif sedikit. Hal ini terjadi diduga karena beberapa faktor antara lain : perencanaan pengembangan hutan kota yang belum optimal; pengetahuan pengelola hutan kota belum sepenuhnya memahami karakteristik jenis-jenis pohon; kolaborasi multi pihak belum berjalan dengan baik dan hal lainnya. Banyaknya jenis pohon penyusun hutan kota selain meningkatkan keanekaragaman jenis juga akan menambah keindahana dan kesejukan.

Meskipun jumlah jenisnya masih sedikit tetapi ada beberapa jenis pohon yang tergolong cukup langka yaitu Gaharu (Aquilaria malaccensis), Pulai Rawa (Alstonia pneumatophore). Tempunik (Artocarpus sp.), Bintangur
(Calophyllum inophyllum), Medang (Cinnamomum sp.), Renghas (Gluta renghas), Balam (Palaqium gutta), Meranti (Shorea sp.) dan Balau (Shorea sumatrana). Jenis-jenis pohon tersebut secara umum sudah cukup sulit ditemukan, karena itu upaya perlindungan perlu dilakukan. Berikut contoh pohon penyusu hutan kota di Kota Pekanbaru seperti pada Gambar 1.
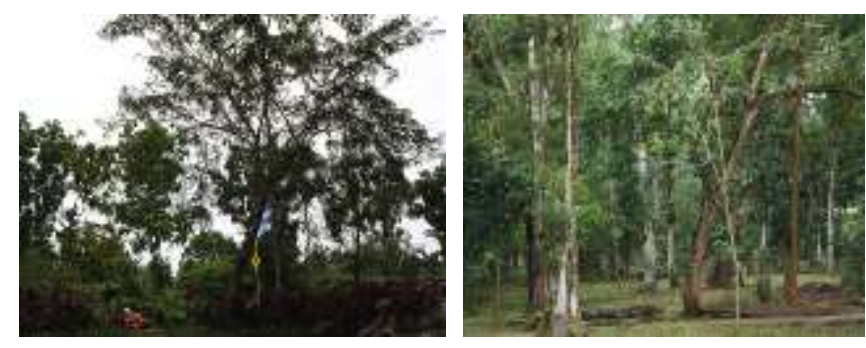

Gambar 1. Pohon Penyusun Hutan Kota di Kota Pekanbaru

\section{Kesesuaian Pemilihan Jenis Pohon}

Pembangunan hutan kota bertujuan untuk kelestarian, keserasian 
dan keseimbangan ekosistem perkotaan yang meliputi unsur lingkungan, sosial ekonomi dan budaya. Untuk kepentingan tersebut, di setiap wilayah perkotaan perlu ditetapkan kawasan tertentu dalam rangka pembangunan hutan kota. Penyelenggaraan hutan kota meliputi beberapa tahap antara lain ; penunjukan, pembangunan, penetapan dan pemeliharaan.

Membangun hutan kota yang baik dan benar tidak hanya untuk menghijaukan dan meningkatkan keindahan lingkungan kota saja, akan tetapi tanaman harus sedapat mungkin mampu mendatangkan banyak manfaat (multi manfaat). Manfaat hutan kota meliputi ekologi, sosial dan ekonomi. Pembangunan hutan kota yang baik dan benar dapat mengatasi masalah lingkungan yang telah muncul ataupun yang akan muncul di kemudian hari. Oleh karena itu tanaman hutan kota harus dapat tumbuh dengan baik, agar fungsinya dapat maksimal. Faktor-faktor yang mempengaruhi kualitas pertumbuhan perlu diperhatikan, baik bibit maupun pemeliharaannya. Selain itu juga faktor alami dan antropogenik perlu mendapat perhatian. Tanaman hutan kota juga harus fungsional, artinya tanaman harus dapat berfungsi dalam pengelolaan lingkungan.

Dengan tanaman itu diharapkan kualitas lingkungan kota dan sekitarnya akan meningkat dan daya dukung kota akan tinggi.

Salah satu tahap awal pengelolaan hutan kota adalah pemilihan jenis pohon hutan kota. Pemilihan jenis pohon ini harus mempertimbangkan persyaratan silvikultural, manajemen dan estetika agar pohon penyusun hutan kota dapat berfungsi optimal sesuai tujuan pembangunan hutan kota. Pemilihan jenis pohon penyusun hutan kota diarahkan pada jenis pohon yang sesuai dengan tempat tumbuh serta efektif dalam pengendalian pencemaran udara atau memiliki daya tahan yang tinggi terhadap paparan polutan. Pada penelitian ini ditemukan 15 jenis pohon $(38,5 \%)$ dengan kriteria sesuai dan 24 jenis pohon $(61,5 \%)$ dengan kriteria cukup sesuai. Berdasar pada hal tersebut secara umum masih cukup sedikit jenis pohon yang sesuai dengan kondisi hutan kota di Kota Pekanbaru. Perlu dilakukan upaya penanaman pengayaan (enrichment planting) di semua lokasi hutan kota dengan berbagai jenis pohon yang sesuai, dan apabila memungkin dilakukan 
penggantian jenis pohon secara bertahap.

Potensi pohon dalam pengendalian pencemaran udara di wilayah perkotaan juga penting untuk dipertimbangkan dalam pengembangan hutan kota. Beberapa contoh jenis tanaman dalam menjerap dan menyerap Timbal (Pb) (Dahlan, 1992) : Kemampuan sedang sampai tinggi : Damar (Agathis alba). Mahoni (Switenia macrophylla), Jamuju (Podocarpus imbricratus), Pala (Mirystica fragran), Asam landi (Pithecelobium dulce), Johar (Cassia siamea); Kemampuan rendah : Glodogan (Polyalthea longifolia), Keben (Baringtonia asiatica), Tanjung (Mimosops elengi); Kemampuan sangat rendah : Daun Kupu-kupu (Bauhinia purpurea), Kesumba (Bixa orellana). Erni (1999) menyatakan bahwa $\mathrm{pH}$ air hujan dari stemflow ataupun throughfall memilki $\mathrm{pH}$ lebih tinggi. Jenis tanaman yang baik untuk meningkatkan $\mathrm{pH}$ air hujan adalah Akasia (Acacia auriculiformis), Kayu Manis (Cinnamomum burmanii), Puspa (Schima walichii) dan Daun Kupu-kupu (Bauhinia purpurea).

Dahlan (1992) menyatakan bahwa tanaman yang baik sebagai penyerap gas $\mathrm{CO}_{2}$ dan penghasil
Oksigen adalah Damar (Agathis alba), Daun Kupu-kupu (Bauhinia purpurea), Lamtorogung (Leucaena leucocephala), Akasia (Acacia auriculiformis) dan Beringin (Ficus benjamina). Sementara jenis pohon yang efektif menyerap karbon monoksida (CO) menurut Kusminingrum (2008) adalah genitri (Elaeocarpus sphaericus), bungur (Lagerstroemia flos-reginae), cempaka (Michelia champaca), bunga merak (Caesalpinia pulcherrima), sapu tangan (Maniltoa grandiflora), tanjung (Mimusops elengi), kupu-kupu (Bauhiniapurpurea), dan kecrutan (Spathodea campanulata).

Menurut Sulistijorini (2009), jenis pohon yang efektif dalam penyerapan nitrogen dioksida $\left(\mathrm{NO}_{2}\right)$ dari udara adalah flamboyan (Delonix regia), tanjung (Mimusops elengi), angsana (Pterocarpus indicus), kayu manis (Cinnamomum burmanii), mahoni (Swietenia macrophylla), bungur (Lagerstroemia speciosa), dan melina (Gmelina arborea). Sementara menurut Siringoringo (2000), jenis pohon yang memiliki kemampuan menjerap partikulat timbal (Pb) dengan kemampuan tinggi adalah johar (Cassia multijuga), kemampuan sedang adalah akasia (Acacia auriculiformis) dan kayu 
manis (Cinnamomum subavenium), sementara yang memiliki kemampuan rendah, yaitu mangium (Acacia mangium) dan kupu-kupu (Bauhinia purpurea).

Pada lokasi penelitian terdapat 15 jenis pohon penyusun hutan kota sebagai pengendali pencemaran udara. Jenis-jenis pohon tersebut efektif menyerap pencemar udara yaitu : timbal $(\mathrm{Pb})$, karbon dioksida $\left(\mathrm{CO}_{2}\right)$, karbon monoksida (CO) dan nitrogen dioksida $\left(\mathrm{NO}_{2}\right)$. Jenis-jenis pohon penyerap polutan seperti tercantum pada Tabel 5 .

\section{Tabel 5. Jenis-Jenis Pohon Penyusun Hutan Kota Sebagai Penyerap Polutan}

\begin{tabular}{|c|c|c|c|c|c|c|c|}
\hline \multirow[b]{2}{*}{$\begin{array}{l}N \\
0\end{array}$} & \multicolumn{2}{|c|}{$\begin{array}{c}\text { Nama Jenis } \\
\text { Pohon }\end{array}$} & \multirow[b]{2}{*}{ Famili } & \multicolumn{4}{|c|}{ Penyerap } \\
\hline & IImiah & $\begin{array}{l}\text { Daera } \\
\text { h/lokal }\end{array}$ & & $\begin{array}{l}P \\
b\end{array}$ & $\begin{array}{l}\text { C } \\
\text { O }\end{array}$ & $\begin{array}{l}\text { C } \\
0\end{array}$ & $\begin{array}{l}\mathbf{N} \\
\mathbf{O}\end{array}$ \\
\hline 1 & $\begin{array}{l}\text { Acacia } \\
\text { auriculi } \\
\text { formis }\end{array}$ & $\begin{array}{l}\text { Akasia } \\
\text { Aurikul } \\
\text { formis }\end{array}$ & $\begin{array}{l}\text { Fabace } \\
\text { ae }\end{array}$ & $\sqrt{ }$ & $\sqrt{ }$ & - & $\sqrt{ }$ \\
\hline 2 & $\begin{array}{l}\text { Acacia } \\
\text { mangiu } \\
m\end{array}$ & $\begin{array}{l}\text { Akasia } \\
\text { Mangi } \\
\text { um }\end{array}$ & $\begin{array}{l}\text { Fabace } \\
\text { ae }\end{array}$ & $\sqrt{ }$ & $\sqrt{ }$ & - & $\sqrt{ }$ \\
\hline 3 & $\begin{array}{l}\text { Artocar } \\
\text { pus } \\
\text { heterop } \\
\text { hylla }\end{array}$ & $\begin{array}{l}\text { Nangk } \\
\text { a }\end{array}$ & $\begin{array}{l}\text { Morace } \\
\text { ae }\end{array}$ & - & $\sqrt{ }$ & - & - \\
\hline 4 & $\begin{array}{l}\text { Casuar } \\
\text { ina } \\
\text { equiset } \\
\text { ifolia }\end{array}$ & $\begin{array}{l}\text { Cemar } \\
\text { a }\end{array}$ & $\begin{array}{l}\text { Casuari } \\
\text { naceae }\end{array}$ & $\sqrt{ }$ & - & - & - \\
\hline 5 & $\begin{array}{l}\text { Cinna } \\
\text { momu } \\
m s p .\end{array}$ & $\begin{array}{l}\text { Medan } \\
\mathrm{g}\end{array}$ & $\begin{array}{l}\text { Laurace } \\
\text { ae }\end{array}$ & - & $\sqrt{ }$ & - & - \\
\hline 6 & $\begin{array}{l}\text { Ficus } \\
\text { elastica }\end{array}$ & $\begin{array}{l}\text { Beringi } \\
n\end{array}$ & $\begin{array}{l}\text { Morace } \\
\text { ae }\end{array}$ & $\sqrt{ }$ & $\sqrt{ }$ & - & - \\
\hline 7 & $\begin{array}{l}\text { Mangif } \\
\text { era } \\
\text { indica }\end{array}$ & $\begin{array}{l}\text { Mangg } \\
\text { a }\end{array}$ & $\begin{array}{l}\text { Anacar } \\
\text { diaceae }\end{array}$ & $\sqrt{ }$ & - & - & - \\
\hline
\end{tabular}

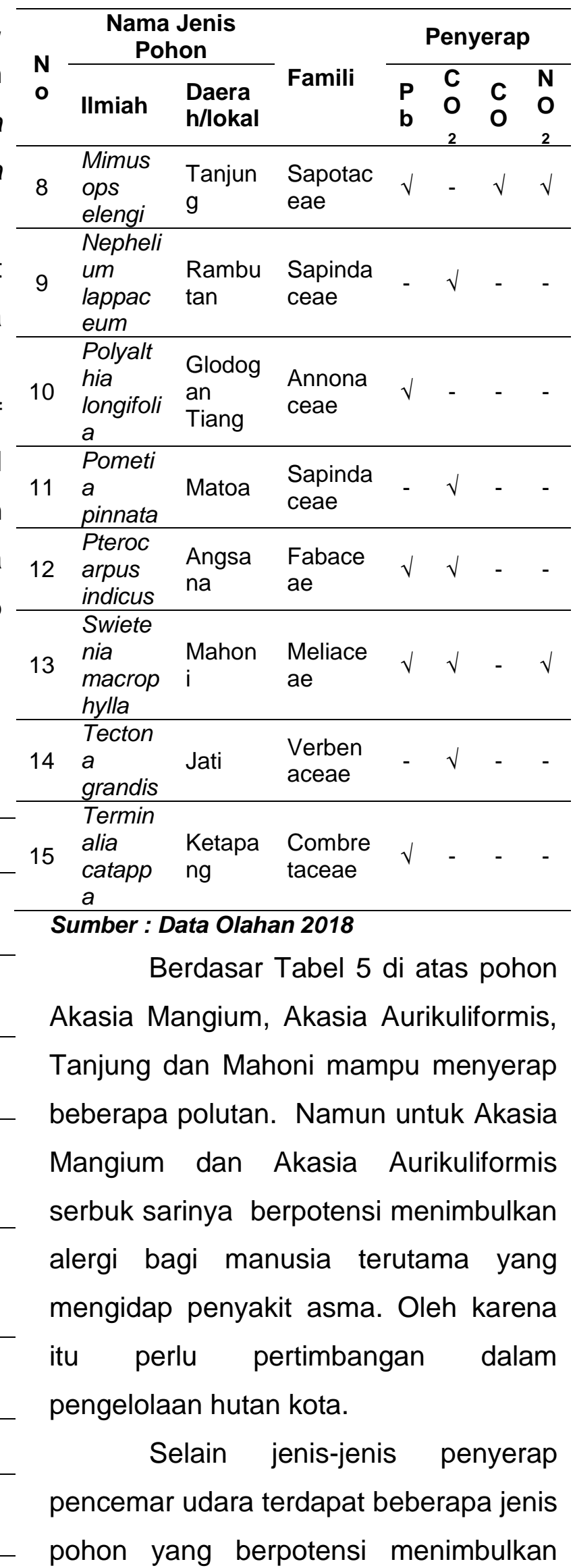


permasalahan bagi pengunjung hutan kota antara lain : Durian, Renghas, Mangga dan Nangka. Pohon Durian memiliki buah yang cukup besar dan berduri, hal ini akan sangat berbahaya apabila buahnya jatuh kepada pejalan kaki/ pengunjung hutan kota. Pohon Mangga dan Nangka juga memiliki buah yang relatif besar dan bergetah sehingga dapat membahayakan pengunjung terutama anak-anak. Pohon Renghas memiliki getah yang gatal sehinga ketika terkena pejalan kaki/ pengunjung hutan kota akan berbahaya.

\section{KESIMPULAN DAN SARAN}

\section{Kesimpulan}

Berdasar pada hasil penelitian dapat disimpulkan sebagai berikut:

1. Tipe hutan kota di Kota Pekanbaru adalah perlindungan dan rekreasi dengan bentuk mengelompok/ gerombol dan jalur

2. Terdapat 15 jenis pohon yang memiliki kriteria sesuai berdasar pada persyaratan silvikultural, manajemen dan estetika.

3. Terdapat 15 jenis pohon yang mampu dalam pengendalian pencemaran udara.

\section{Saran}

Diperlukan perencanaan yang optimal dalam mengembangkan hutan kota terutama dalam memilih jenis pohon yang akan ditanam sehingga dapat memberikan multi manfaat bagi masyarakat.

\section{DAFTAR PUSTAKA}

Bosch van den. C.C.K. 2016. "Tree agency and urban forest governance", Smart and Sustainable Built Environment, Vol. 5 Issue: 2, pp.176-188, https://doi.org/10.1108/SASBE07-2015-0017.

Christopoulou $O$, Serafeim $P$, Dionissios M. 2007. "Periurban and urban forests in Greece: obstacle or advantage to urban development?", Management of Environmental Quality: An International Journal, Vol. 18 Issue: 4, pp.382-395, https: //doi.org/10.1108/14777830710 753794.

Dare AM, Idris AA, Adebayo MS. 2015. "Urban trees forest management in Abeokuta Metropolis, Ogun State, Nigeria: An application of contingent valuation method", Management of Environmental Quality: An International Journal, Vol. 26 Issue: 1, pp.72-83, https://doi.org/10.1108/MEQ06-2014-0094. 
Hamzah, Rike PT, Nursanti. 2016. Peningkatan Populasi dan Keragaman Jenis Hutan Kota Dengan Peran Serta Masyarakat di Kota Jambi. Jurnal Pengabdian pada Masyarakat 31: 44-51.

Irwan SNR, Kaharudin. 2010. Studi Kenyamanan untuk Aktivitas di Lanskap Hutan Kota UGM (Studi Kasus : Kluster Argo UGM). Jurnal IImu Kehutanan IV : 98-110.

Karanikola $\mathrm{P}$, Thomas $\mathrm{P}$, Stilianos $\mathrm{T}$, Aikaterini KK. 2016. "A perceptual study of users' expectations of urban green infrastructure in Kalamaria, municipality of Greece", Management of Environmental Quality: An International Journal, Vol. 27 Issue: 5, pp.568-584, https://doi.org/10.1108/MEQ12-2014-0176.

Mukhlison. 2013. Pemilihan Jenis Pohon untuk Pengembangan Hutan Kota di Kawasan Perkotaan Yogyakarta. Jurnal IImu Kehutanan VII : 37-47.

Noviady I, Reza RR. 2015. Identifikasi kondisi kesehatan pohon peneduh di kawasan Ecopark, Cibinong Science CenterBotanic Gardens. Pros Sem Nas Masy Biodiv Indon 1 : 1385-1391.

Samsoedin I, Endro S. 2006. Pembangunan dan Pengelolaan Hutan Kota. Ekspose Hasil-hasil Penelitian : Konservasi dan Rehabilitasi Sumberdaya Hutan. Padang.
Sundari ES. 2005. Studi untuk Menentukan Fungsi Hutan Kota dalam Masalah Lingkungan Perkotaan. Jurnal PWK UNISBA : 68-83. 